Polymer Journal, Vol. 38, No. 7, pp. 686-693 (2006)

(C) 2006 The Society of Polymer Science, Japan

\title{
The Role of Hard Segments of Aqueous Polyurethane-urea Dispersion in Determining the Colloidal Characteristics and Physical Properties
}

\author{
Tsutomu TAWA ${ }^{\dagger}$ and Shinzaburo ITO \\ Department of Polymer Chemistry, Kyoto University, Nishigyo, Kyoto 615-8510, Japan
}

(Received December 15, 2005; Accepted March 4, 2006; Published June 9, 2006)

\begin{abstract}
A series of aqueous polyurethane-urea dispersions (PUDs) were synthesized to investigate the role of hard segments in determining the colloidal properties in water and the physical properties in PUD films. The chemical structures were modified in terms of, the fraction of the hard segment, the intra-chain distance between hard segments, the amount of ionic $\mathrm{COOH}$ group and the type of counterion. The particle size in water decreased with the increase in stabilization of micelles, which was determined by the homogeneity of the distribution of ionic units, flexibility of main chains and hydrophilicity of the neutralized counterions. The physical properties of PUDs were characterized by microphase separation of hard and soft domains. However, the microphase separation structure was not strict at the molecular chain level, that is, the hard domains containing some soft segments and the soft domains containing hard segments existed. The presence of the soft segment in the hard domain lowered the glass transition temperature of the hard domain, consequently affecting the mechanical strength etc., depending on the chain length of soft segment, the content of ionic units, and also on the bulkiness of the counterions. These results will be useful for designing molecular structures of PUDs to obtain the best performance for various applications. [doi:10.1295/polymj.PJ2005193]

KEY WORDS Aqueous Polyurethane-urea Dispersion (PUD) / Microphase Separation / Hard Segment / Colloidal Characteristic / Physical Property /
\end{abstract}

Polyurethane is a unique polymeric material with a wide range of physical and chemical properties. It has been used in various fields, such as foams, coatings, adhesives, and thermoplastic elastomers. These properties originate from the microphase separation structure in polyurethane films because the polyurethane chain consists of soft and hard segments as shown in Figure 1. A hard domain formed by hydrogen bonding of hard segments provides properties of both physical crosslinkage and filler-like reinforcement. ${ }^{1-7}$

Recently, aqueous polyurethane-urea dispersion (PUD) is gathering considerable attention due to the growing concern to preserve the environment. ${ }^{8-15}$ PUD can be prepared by introducing ionic moieties into a polyurethane, neutralizing and then dispersing them into water if a sufficient amount of the ionic moiety is incorporated. The presence of an ionic group in the hard segment has a considerable effect on its physical properties and it is reasonable to suppose that the interaction between acid groups and their counterions is responsible for these effects. The degree of neutralization, ${ }^{16-19}$ the type of counterion, ${ }^{20-24}$ and the amount of ionic compound ${ }^{25,26}$ significantly influence the physical properties.

In this paper, we report the role of the hard segment of PUD investigated by using a few series of PUDs, which were prepared to have different distances and fractions of hard segments, the amount of ionic groups and the type of counterions. After examining the colloidal characteristics and the physical properties of these PUDs in relation to the chemical structures, we discuss the role of hard segments from the molecular side.

\section{EXPERIMENTAL}

\section{Materials}

Polycarbonate diol (PC) was dried under $\mathrm{N}_{2}$ bubbling at $75^{\circ} \mathrm{C}$ for 4 h. 2,2-Dimethyl-1,3-propanediol (NPG, Wako Pure Chemical Industries, Ltd.) was dried under an $\mathrm{N}_{2}$ atmosphere for more than 3 days. 1,3-Bis(isocyanatemethyl)cyclohexane (H6XDI, Mitsui-Takeda Chemical Industries, Ltd.), dimethylol propionic acid (DMPA), hydrazine monohydrate (HD, Wako Pure Chemical Industries, Ltd.), triethylamine (TEA, Wako Pure Chemical Industries, Ltd.), triisopropanolamine (TIPA, Wako Pure Chemical Industries, Ltd.), 2-dimethylaminoethanol (DMEA, Wako Pure Chemical Industries, Ltd.) and sodium hydrate $(\mathrm{NaOH}$, Wako Pure Chemical Industries, Ltd.) were used without further purification.

\section{Preparation of Aqueous Polyurethane-urea Disper- sion}

PUD was prepared as follows. A $500 \mathrm{~mL}$ four-neck round-bottom flask equipped with a stirrer, a ther-

${ }^{\dagger}$ To whom correspondence should be addressed (Tel: +81-75-383-2614, Fax: +81-75-383-2617, E-mail: tawa@ photo.polym.kyoto-u.ac.jp). 


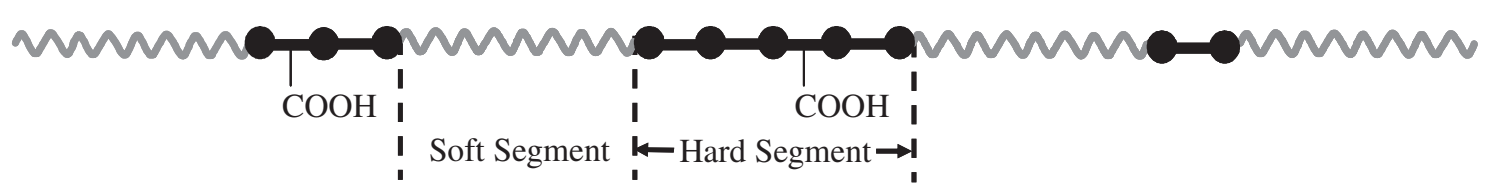

Macropolyol

Polycarbonatediol (PC)

$\mathrm{O}$
$\mathrm{HO}-\left(\left(\mathrm{CH}_{2}\right)_{6}-\mathrm{OCO}\right)_{\mathrm{n}}-\mathrm{H}$

Low molecular weight compounds

2,2-dimethyl-1,3-propanediol (NPG)

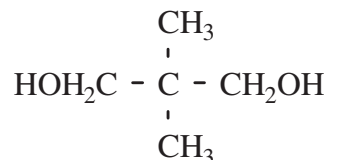

Hydrazine (HD)

$\mathrm{H}_{2} \mathrm{~N}-\mathrm{NH}_{2}$

Dimethyrol propionic acid (DMPA)

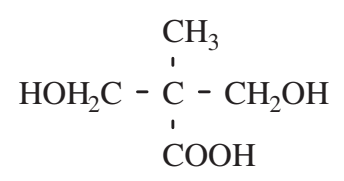

Isocyanate

1,3-Bis(isocyanatemethyl)cyclohexane (H6XDI)<smiles>O=NCC1CCCC(CN=O)C1</smiles>

Figure 1. Schematic polyurethane-urea chain.

mometer, a nitrogen inlet, and a condenser was charged with H6XDI (194.00 g, $1.0 \mathrm{~mol}$ ) and acetonitrile $(217.01 \mathrm{~g})$ under nitrogen atmosphere. PC $\left(M_{\mathrm{n}}=\right.$ 2,000, $246.91 \mathrm{~g}, 0.123 \mathrm{~mol}), \mathrm{NPG}(25.73 \mathrm{~g}, 0.247 \mathrm{~mol})$ and DMPA $(39.70 \mathrm{~g}, 0.296 \mathrm{~mol})$ were then added while stirring slowly, and the mixture was heated to $70{ }^{\circ} \mathrm{C}$. They were allowed to react until the theoretical NCO content was detected by the dibuthylamine back-titration method (ASTM D 1638). The NCOterminated prepolymer thus obtained was poured into an aqueous solution of tertially amines or $\mathrm{NaOH}$ as the neutralizing agent (counterions) under constant agitation $(2,000 \mathrm{rpm})$. This dispersion was kept at $20^{\circ} \mathrm{C}$ for $20 \mathrm{~min}$ to complete the neutralization reaction. DMEA, TEA, TIPA and $\mathrm{NaOH}$ were used as counterions. The stoichiometric ratio of counterions to $\mathrm{COOH}$ was 0.95 . The neutralized $\mathrm{NCO}$ terminated polyurethane prepolymer was extended by adding a $10 \%$ hydrazine monohydrate solution. The stoichiometric ratio of the amine group of hydrazine to $\mathrm{NCO}$ of the prepolymer was 0.95 . The PUD $(30 \mathrm{wt} \%$ concentration) was obtained by the evaporation of acetonitrile and then by adding an adequate amount of water. Table I shows the sample designation and composition. Samples were named so that, for example in DM-20-2, the initial letter 'DM' refers to the counterion DMEA, 20 to the molecular weight 2000 of PC, and 2 to the $\mathrm{COOH}$ group weight content (\%) in this polyurethane-urea dispersion.

\section{Film Preparation}

Film samples for mechanical and viscoelastic measurements were prepared by casting the dispersions on a metal plate under ambient conditions. The films (about $0.1 \mathrm{~mm}$ thickness) were dried for longer than $1 \mathrm{~d}$ to avoid producing foam or bubbles in the film at annealing. When the aqueous dispersion forms the transparent film, the film formation process consists of three steps, water evaporation, particle deformation and particle coalescence. ${ }^{27-29}$ The mechanical properties are influenced by the condition of the film formation process. Furthermore, the microphase separation state also affects the mechanical properties, since the polyurethane, consisting of a soft and hard segment, takes the microphase separation structure. The film formation process and the microphase separation state are influenced by temperature being one of the annealing conditions. The temperature dependency of mechanical properties examined using DM-20-2 for 1 annealing hour showed the almost the same stressstrain (SS) curves above $110^{\circ} \mathrm{C}$. This result indicates that the disconnected PUD particles fully coalesce, are diffused mutually and formed the transparent film with the stable microphase separation structure above $110^{\circ} \mathrm{C}$ for 1 annealing hour. On the basis of this experimental data, the annealing condition was determined at $130^{\circ} \mathrm{C}$ for $1 \mathrm{~h}$.

\section{Measurements}

The average particle size was measured by light 
Table I. The designation and composition (mol ratio) of aqueous polyurethane-urea dispersions (PUD)

\begin{tabular}{lccccccc}
\hline \multirow{2}{*}{ PUD } & \multicolumn{3}{c}{ Polymer composition (mol ratio) } & \multicolumn{2}{c}{$\begin{array}{c}\text { Counterion } \\
(0.95 \text { eq. })\end{array}$} & $\begin{array}{c}\text { COOH weight } \\
\text { content }(\%)\end{array}$ & $\begin{array}{c}\text { Hard segment weight } \\
\text { fraction }(\%)\end{array}$ \\
\cline { 2 - 4 } Series M & H6XDI & PC & NPC & DMPA & & & 52.6 \\
DM-20-2 & 8.1 & 1 & 2 & 2.4 & DMEA & 2.6 & 55.8 \\
DM-10-2 & 9.6 & 2 & 2 & 2.4 & DMEA & 2.4 & 68.7 \\
DM-10-2H & 8.1 & 1 & 2.6 & 1.8 & DMEA & 2.5 & 52.3 \\
Series C & & & & & & & 52.6 \\
DM-20-1 & 8.1 & 1 & 2.9 & 1.5 & DMEA & 1.6 & 52.9 \\
DM-20-2 & 8.1 & 1 & 2 & 2.4 & DMEA & 2.6 & 5.6 \\
DM-20-3 & 8.1 & 1 & 1 & 3.4 & DMEA & & 52.6 \\
Series N & & & & & & & 52.6 \\
DM-20-2 & 8.1 & 1 & 2 & 2.4 & DMEA & 2.6 & 52.6 \\
TE-20-2 & 8.1 & 1 & 2 & 2.4 & TEA & 2.6 & 52.6 \\
TI-20-2 & 8.1 & 1 & 2 & 2.4 & TIPA & 2.6 & 2.6 \\
Na-20-2 & 8.1 & 1 & 2 & 2.4 & Na & & 5 \\
\hline
\end{tabular}

The polyurethane prepolymer was prepared at $\mathrm{NCO}: \mathrm{OH}=1.5: 1$ ratio. The PUD was prepared by the chain-extending reaction between $\mathrm{NCO}$ group of polyurethane prepolymer and $\mathrm{NH}_{2}$ group of hydrazine monohydrate. The ratio of $\mathrm{NCO}$ group of polyurethane prepolymer to $\mathrm{NH}_{2}$ group of hydrazine monohydrate is 1 to 0.85 .

scattering (Coulter N4 Plus), where a He-Ne laser with a wavelength of $632.8 \mathrm{~nm}$ was used. The sample was diluted in deionized water to adjust the concentration for measurement.

Viscoelastic properties of films were measured at 10 $\mathrm{Hz}$ using a DVA-200 instrument (IT Keisokuseigyo) at a heating rate of $5{ }^{\circ} \mathrm{C} / \mathrm{min}$ in the temperature range from -100 to $200^{\circ} \mathrm{C}$.

Mechanical properties were measured at $25^{\circ} \mathrm{C}$ using INTESCO Model 205 following the ASTM D-412 specifications. A crosshead speed of $300 \mathrm{~mm} /$ min was used throughout these investigations to determine the ultimate tensile strength and elongation at break for all the samples. The values quoted are the average of five measurements.

\section{RESULTS AND DISCUSSION}

\section{Distance and Fraction of Hard Segment}

In the polyurethane-urea molecule, the hard segment consists of urethane linkage generated by the reaction between H6XDI and low molecular weight diol or HD, and the soft segment is formed from macropolyol PC as shown in Figure 1. In a solid film, the hard segments aggregate by hydrogen bonding and form a hard domain. Therefore, the fraction of the hard segment in a polymer chain affects the number and the size of the hard domain. On the other hand, the length of soft segment, which is dependent on the PC molecular weight, determines the distance between the hard segments. In order to consider the influence of fraction and distance of the hard segments, three samples were prepared. Table I shows the specifications for these samples (Series M: DM-20-2, DM-10-2 and DM-10-
$2 \mathrm{H})$. The length of the soft segment in DM-20-2 was different from that in DM-10-2, but the weight fraction of the hard segment was kept constant by adjusting low molecular weight diols. Therefore, the mol ratio of PC in DM-10-2 was twice that in DM-20-2. In contrast, the mol ratio of PC to low molecular weight diol (NPG and DMPA) was kept constant for DM-20-2 and $\mathrm{DM}-10-2 \mathrm{H}$, consequently increasing the weight fraction of the hard segment from 52.6 to 68.7. The last letter ' $\mathrm{H}$ ' of DM-10-2H indicates that DM-10-2H has a larger hard segment fraction than the other samples. The differences of the three samples are schematically illustrated in Figure 2.

First, we discuss the colloidal characteristics of PUDs. Table II shows the particle sizes of the PUDs. By comparing the particle sizes of DM-20-2 and DM$10-2 \mathrm{H}$, we found that the particle size increases as the molecular weight of soft segment decreases. It is known that the ionic groups are located predominantly on the surface of particles and the ionomer dispersions are stabilized by the formation of electrical double layers. As the polyurethane chain becomes harder with decreasing length of soft segment, the formation of polymer micelles in water needs more chains to stabilize the micelle structure. In contrast with this result, the particle size decreased with the decrease of the soft segment length from DM-20-2 to DM-10-2 while the weight fraction of soft segment is fixed. This result was explained as an effect of homogeneous $\mathrm{COOH}$ group in a molecule. The smaller the molecular weight of $\mathrm{PC}$ is, the more uniformly the $\mathrm{COOH}$ group can be distributed. The uniform distribution of $\mathrm{COOH}$ group makes the formation of micelle easy, consequently the particle size becomes small. 

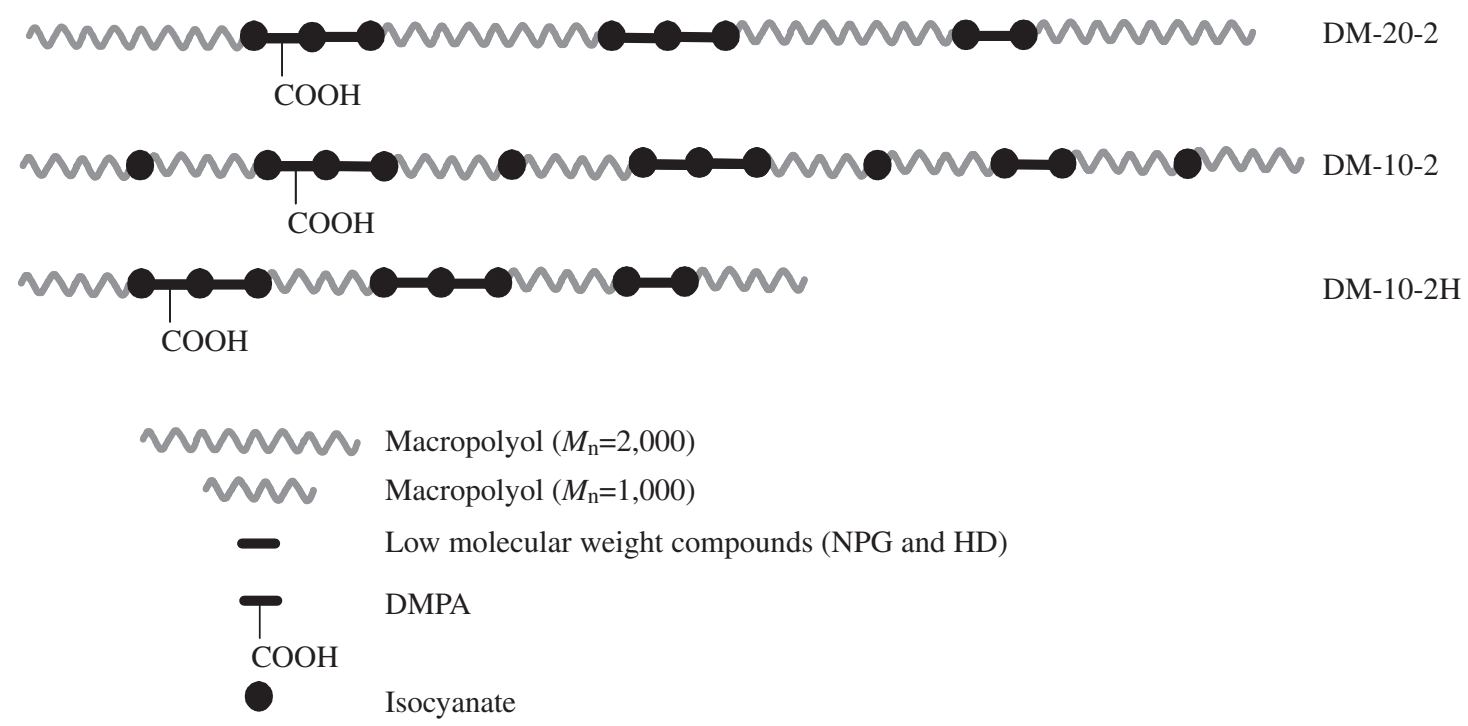

Figure 2. Illustration of the difference among three samples: DM-20-2 (top), DM-10-2 (middle) and DM-10-2H (bottom).

Table II. The colloidal and physical properties of aqueous polyurethane-urea dispersions (PUDs)

\begin{tabular}{|c|c|c|c|c|c|c|}
\hline Sample & $\begin{array}{l}\text { Particle size } \\
(\mathrm{nm})\end{array}$ & $\begin{array}{l}T_{\mathrm{gs}} \\
\left({ }^{\circ} \mathrm{C}\right)\end{array}$ & $\begin{array}{l}T_{\mathrm{gh}} \\
\left({ }^{\circ} \mathrm{C}\right)\end{array}$ & $\begin{array}{c}\text { Tensile strength } \\
\text { (MPa) }\end{array}$ & $\begin{array}{l}\text { Young's modulus } \\
(\mathrm{MPa})\end{array}$ & $\begin{array}{c}\text { Strain at break } \\
(\%)\end{array}$ \\
\hline \multicolumn{7}{|l|}{ Series M } \\
\hline DM-20-2 & 55.7 & -29.0 & 118 & 47.2 & 236 & 388 \\
\hline DM-10-2 & 23.0 & -14.5 & 105 & 50.6 & 313 & 391 \\
\hline DM-10-2H & 115.0 & -7.0 & 122 & 57.2 & 388 & 17 \\
\hline \multicolumn{7}{|l|}{ Series C } \\
\hline DM-20-1 & 99.2 & -28.7 & 116 & 47.8 & 200 & 365 \\
\hline DM-20-2 & 55.7 & -29.0 & 118 & 47.2 & 236 & 388 \\
\hline DM-20-3 & 44.1 & -28.3 & 122 & 46.6 & 271 & 335 \\
\hline \multicolumn{7}{|l|}{ Series N } \\
\hline DM-20-2 & 55.7 & -29.0 & 118 & 47.2 & 236 & 388 \\
\hline TE-20-2 & 112 & -28.5 & 108 & 43.7 & 296 & 386 \\
\hline TI-20-2 & 57.6 & -28.0 & 108 & 40.4 & 229 & 373 \\
\hline $\mathrm{Na}-20-2$ & 49.0 & -28.5 & 130 & 52.0 & 210 & 390 \\
\hline
\end{tabular}

In viscoelastic properties, there are large differences among the three samples, as shown in Figure 3. Table II shows the $T_{\mathrm{g}}$ values determined from the maxima of $\tan \delta$. Two peaks are observed in the $\tan \delta$ curves. The lower temperature peak is considered as the glass transition temperature of the soft domains $\left(T_{\mathrm{gs}}\right)$ and the higher temperature peak is that of hard domains $\left(T_{\mathrm{gh}}\right)$. The comparison between DM-202 and DM-10-2 indicates that $T_{\text {gh }}$ of DM-20-2 is higher than that of DM-10-2 and $T_{\mathrm{gs}}$ is opposite. These results can be explained as shown in Figure 4. Some hard segments existed in the soft domains and some soft segments existed in the hard domains, because the hard segments were more uniformly distributed in DM-10-2 due to the short length of the soft segment. Therefore, $T_{\mathrm{gs}}$ increases under the influence of hard segments and $T_{\mathrm{gh}}$ decreases under the influence of soft segments.

DM-10-2H had the highest $T_{\mathrm{gs}}$ among the three samples due to the largest fraction of hard segments. It is interesting that $T_{\mathrm{gs}} \mathrm{s}$ were quite different but $T_{\text {gh }}$ S were almost the same at $120^{\circ} \mathrm{C}$ for DM-20-2 and DM-10-2H. These results obtained on DM-20-2 show that there are few soft segments in the hard domains, and the phase separation proceeds almost completely both in the hard and soft domains.

Figure 5 and Table II show the mechanical properties of these three samples DM-10-2H shows the most peculiar stress-strain curve of the three samples. The largest Young's modulus (388 MPa) and extremely small elongation are caused by the high fraction of hard segment in DM-10-2H. On the other hand, although the length of the soft segment is short in DM-10-2, it shows almost the same elongation as 


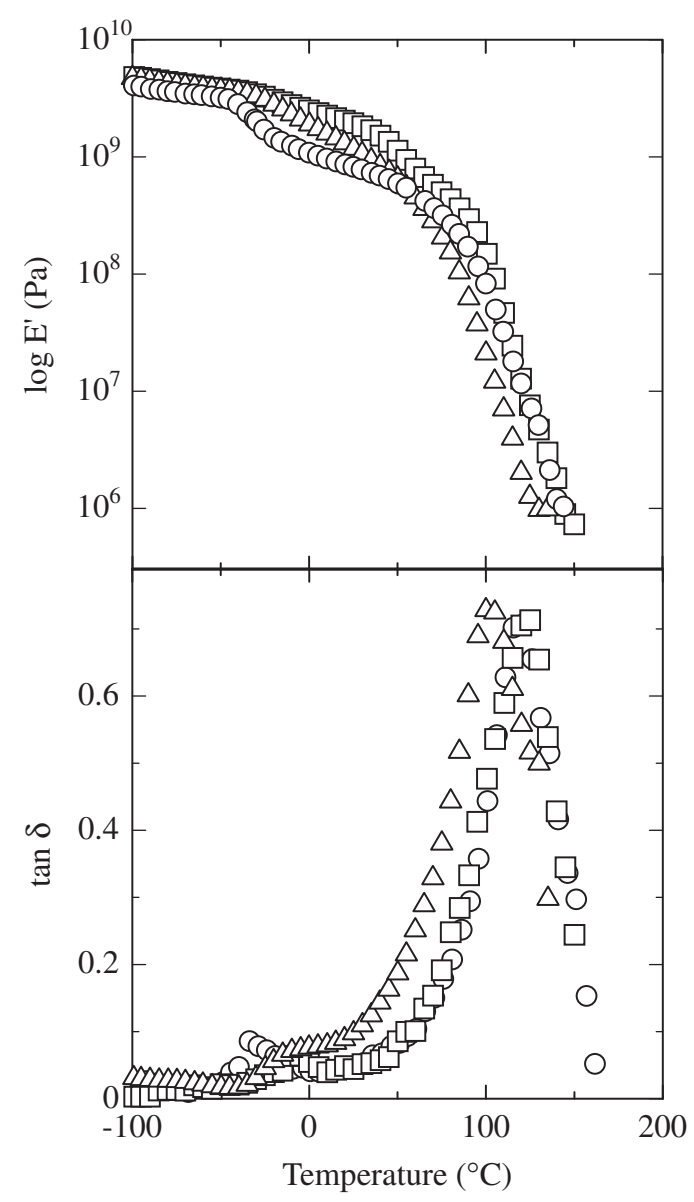

Figure 3. Storage modulus $\left(\mathrm{E}^{\prime}\right)$ and $\tan \delta$ for PUDs: $(\bigcirc)$ DM20-2, ( $\triangle$ ) DM-10-2, ( $\square)$ DM-10-2H.
DM-20-2. This result shows that two PCs connected by urethane linkage, as shown in Figure 2, behave as a long chain of the soft segment to large deformation. However, the Young's modulus has a big difference between DM-10-2 (313 MPa) and DM-20-2 (236 MPa). This is the contribution as the hard segment of the urethane linkage connecting two PCs. Therefore, the hard segment has larger influence in minute deformation.

\section{Amount of Ionic Compounds}

In the previous section, we focused on the distance

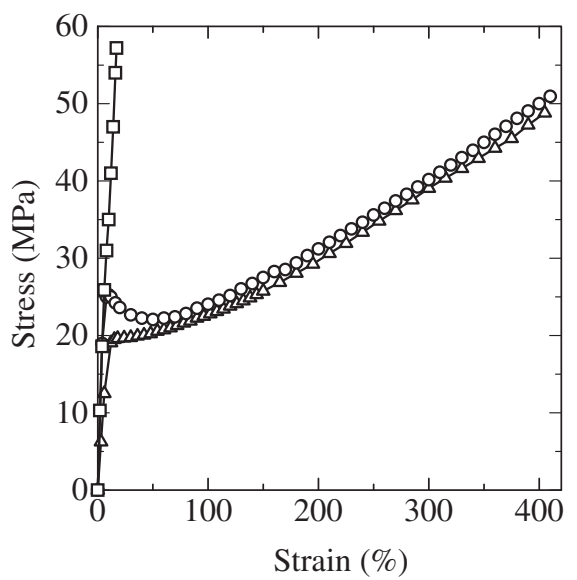

Figure 5. Stress-strain curves for PUDs: (O) DM-20-2, $(\triangle)$ DM-10-2 and $(\square)$ DM-10-2H.

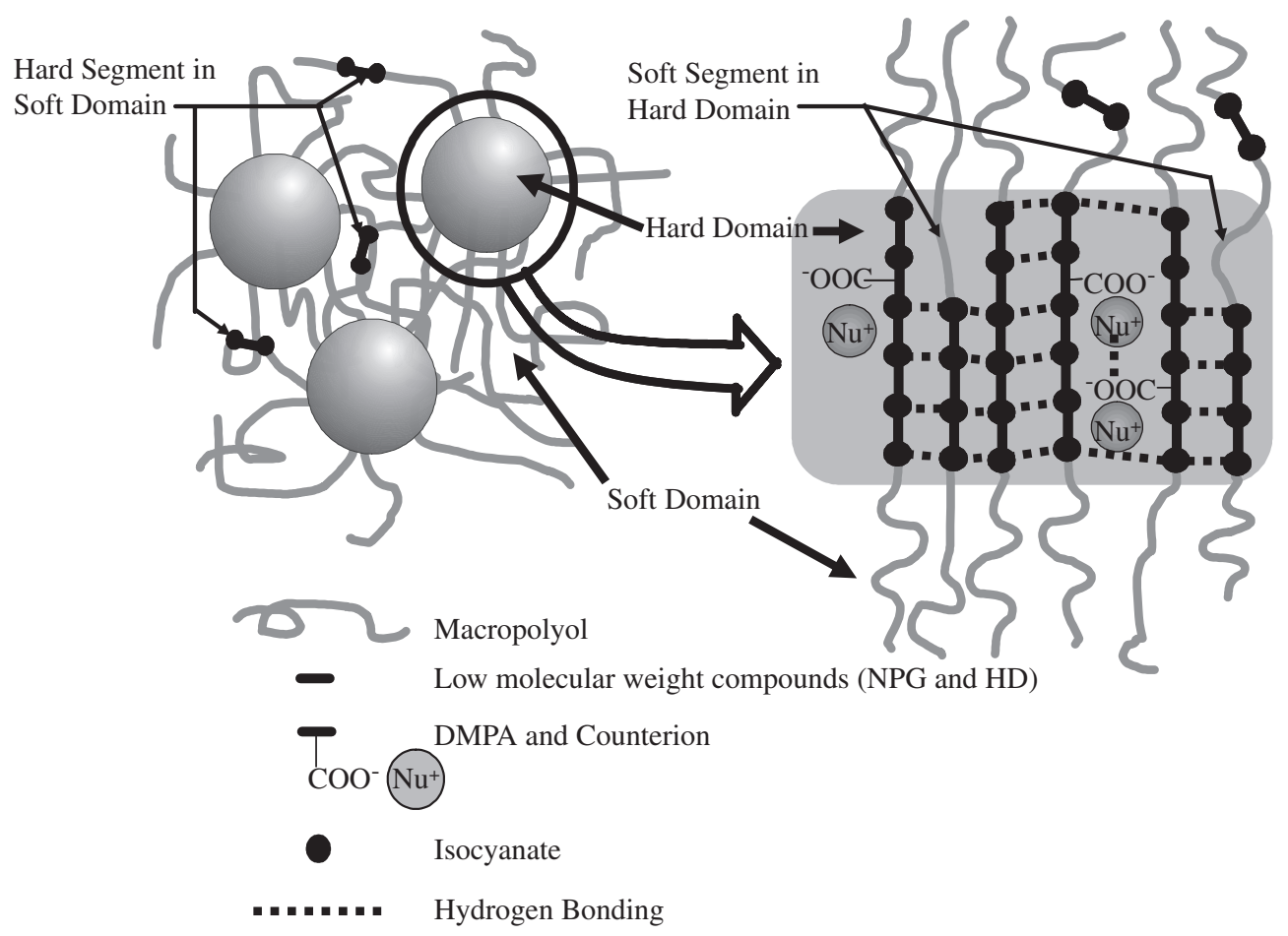

Figure 4. Schematic illustration for the microphase separation structure of a film produced from the PUD. 

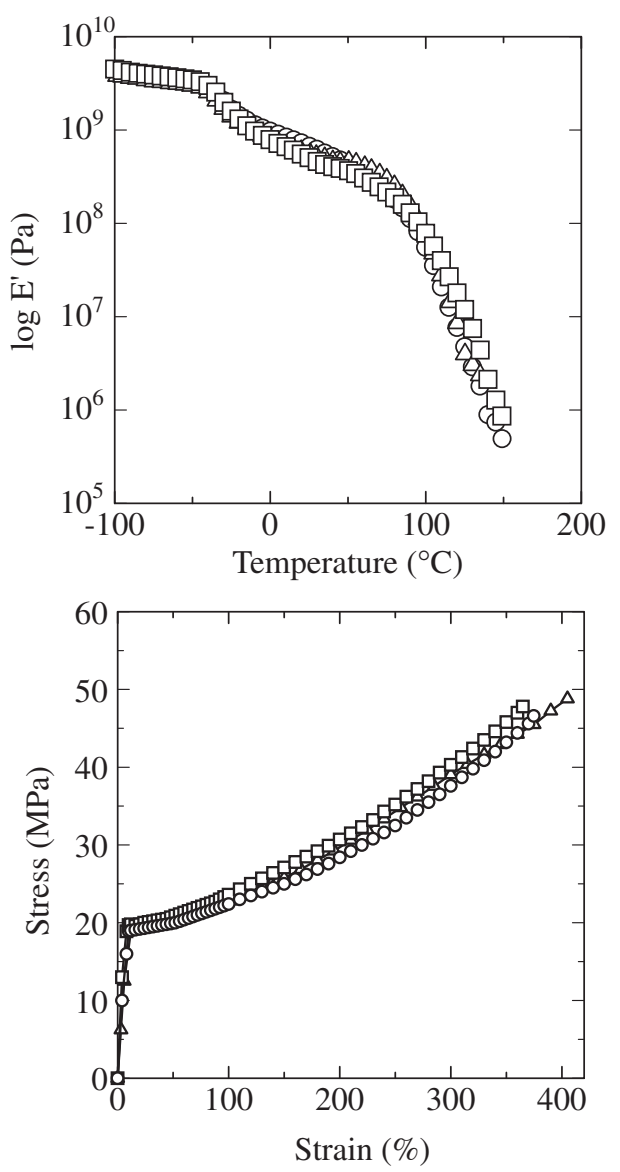

Figure 6. Storage modulus $\left(\mathrm{E}^{\prime}\right)$ and stress-strain curves for PUDs with different amounts of $\mathrm{COOH}$ group: (O) DM-20-1, $(\triangle)$ DM-20-2 and ( $\square$ ) DM-20-3.

and the fraction of hard segments in a polyurethane chain. In this section, we changed the amount of ionic $\mathrm{COOH}$ group in order to examine the cohesive force of the hard segment. The three samples of series $\mathrm{C}$ in Table I (DM-20-1, DM-20-2 and DM-20-3) were prepared to have $\mathrm{COOH}$ contents of $1.6,2.6$, or 3.6 wt $\%$ based on total solid. In colloidal characteristics, particle size decreased with increasing $\mathrm{COOH}$ content, as shown in Table II. Since the particle is stabilized by the hydrophilic groups in PUD ${ }^{8}$ it is natural for the particle size to become smaller as the $\mathrm{COOH}$ content increases.

Figure 6 shows the dynamic modulus and the stressstrain curves of three samples, and Table II shows $T_{\mathrm{gh}} \mathrm{S}$. As shown in Table I, the hard segment fractions were almost the same among the three samples. Dynamic modulus, stress-strain curves and Young's modulus hardly changed among the three samples even when the content of hydrophilic DMPA increased. Only $T_{\text {gh }}$ slightly rises with the increase of $\mathrm{COOH}$ content. These results show that microphase separation proceeds completely when the length of soft segment is long. Perhaps the $\mathrm{COOH}$ group contributes to promote microphase separation more strongly as com- pared with other nonionic species. However, in this experiment the condensed state of hard segments was not influenced by the $\mathrm{COOH}$ content, since microphase separation proceeds depending completely on the presence of long chain hydrophobic PC.

\section{Type of Counterion}

The type of counterion also affects the physical properties of PUDs. In this section, we discuss series $\mathrm{N}$ in Table I. As to colloidal characteristics, TE-20-2 with the TEA counterion had a large particle size $(112 \mathrm{~nm})$ in comparison with the other dispersions with Na, DMEA and TIPA counterions. TEA had the weakest hydration ability among them because it has the hydrophobic ethylene group, but DMEA and TIPA have the hydrophilic hydroxyl units. Na-20-2 has the smallest particle size because it has the strongest hydrated ability of metal cations among the four samples.

Figure 7 shows the $\tan \delta$ values and the stress-strain curves of N-series samples. $T_{\mathrm{gs}} \mathrm{s}$ of four samples are almost the same, because the same PC was employed as the soft segment. On the other hand, $T_{\mathrm{gh}} \mathrm{S}$ and mechanical properties were in the decreasing order
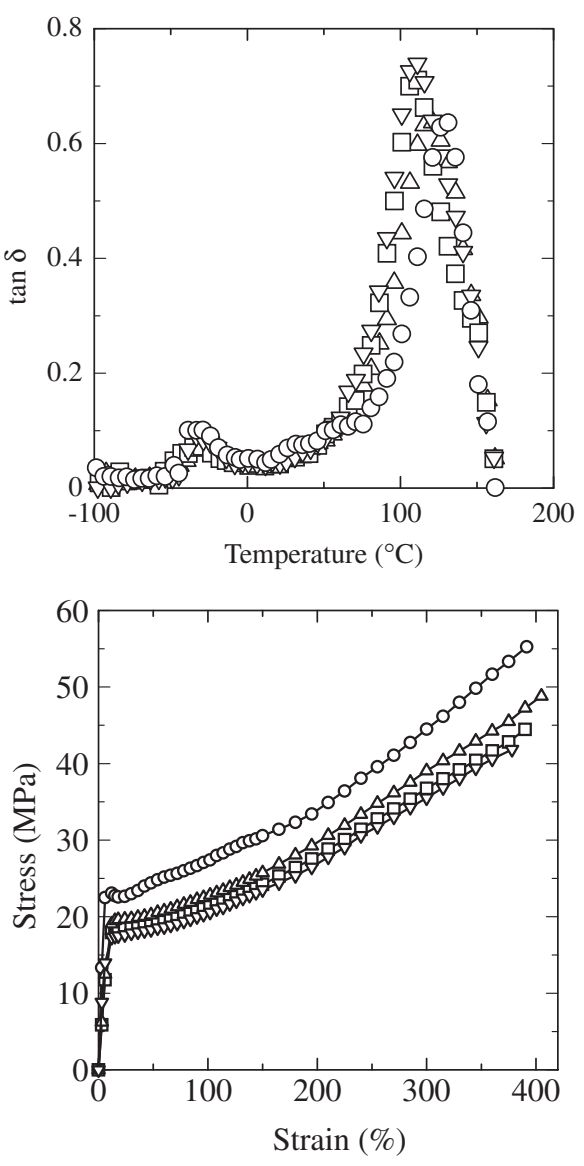

Figure 7. Tan $\delta$ and stress-strain curves for PUDs with different counterions: $(\bigcirc)$ Na-20-2, $\triangle$ ) DM-20-2, ( $\square$ ) TE-20-2 and $(\nabla)$ TI-20-2. 
of Na, DMEA, TEA and TIPA. These results indicate that counterions affect the condensed state of the hard segment. Assuming that the size of counterion is proportional to the molecular weight, their size increases in the order of Na (23), DMEA (89), TEA (101), and TIPA (192). This is consistent with the order of $T_{\mathrm{gh}} \mathrm{S}$, suggesting that the mechanical properties and Young's modulus are subjected to the plasticizing capacity of the counterion. It exists near the $\mathrm{COOH}$ group in the hard domains as shown in Figure 4, and the effect as a plasticizer in the hard domain becomes larger as its size becomes large, resulting in a weak cohesive force between the hard segments.

\section{CONCLUSION}

Differences in the fraction and distance of hard segments, the amount of $\mathrm{COOH}$ groups and the type of counterions appeared as the colloidal characteristics and physical properties of three series of PUDs.

The hard segment affected the colloidal characteristics of PUD. The increase in the fraction of hard segment enlarged the particle size of PUD micelles, because the polyurethane chain becomes harder with increasing fraction of hard segment and the formation of polymer micelles in water needs more chains to stabilize the micelle structure. Under a certain fraction of the hard segment, the homogeneous distribution of $\mathrm{COOH}$ group in the polyurethane chain results in a small particle size. The amount of $\mathrm{COOH}$ groups as hydrophilic unit also influenced the particle size of PUD, indicating that the larger amount of $\mathrm{COOH}$ groups led to the smaller particle size of PUD. Moreover, the hydrophilicity and hydration ability of the counterions affected the particle size of PUD.

In physical properties, the role of the hard segment is more important. The results of viscoelastic measurement showed that PUD had a microphase separation structure and two $T_{\mathrm{g}} \mathrm{s}: T_{\mathrm{gh}}$ derived from the hard domain and $T_{\mathrm{gs}}$ from the soft domain. The distance of the hard segments affected the microphase separation structure, resulting in an increase in $T_{\mathrm{gs}}$ and decrease in $T_{\mathrm{gh}}$ by the mutual penetration of the hard and soft segments into the soft and hard domains with the reduction of the distance between the hard segments. In mechanical properties, the influence of the hard segment appears most clearly in the Young's modulus. And the increase of the fraction of hard segment led to the high modulus and short elongation.

The component in hard segments, such as the amount of the $\mathrm{COOH}$ unit and the type of counterions, influenced the $T_{\mathrm{gh}}$. The $T_{\mathrm{gh}}$ slightly rose with the increase of $\mathrm{COOH}$ content due to promotion of micro- phase separation by hydrogen bonding of the ionic $\mathrm{COOH}$ species. Furthermore, $T_{\text {gh }}$ and Young's modulus were influenced by the plasticizing capacity proportional to the size of counterion.

These experimental results indicate that the detailed internal structure in the hard domain, as illustrated in Figure 4, is important knowledge for designing the chemical structure of PUDs.

\section{REFERENCES}

1. S. Sakurai, Y. Okamoto, H. Sakaue, T. Nakamura, L. Banda, and S. Nomura, J. Polym. Sci., Part B: Polym. Phys., 38, 1716 (2000).

2. W. Tang, R. J. Farries, W. J. Macknight, and C. D. Eisenbach, Macromolecules, 27, 2814 (1994).

3. G. Consolati, M. Levi M, and S. Turri, Polymer, 42, 9723 (2001).

4. M. F. Sonnenschein, N. Rondan, B. L. Wendt, and J. M. Cox, J. Polym. Sci., Part A: Polym. Chem., 42, 2715 (2004).

5. D. J. Martin, G. F. Meijs, G. M. Renwick, S. J. Mccarthy, and P. A. Gunatillake, J. Appl. Polym. Sci., 62, 1377 (1996).

6. H. Tan, M. Guo, R. Du, X. Xie, J. Li, Y. Zhong, and Q. Fu, Polymer, 45, 1647 (2004).

7. L. F. Wang and Y. H. Wei, Colloids Surf., B, 41, 249 (2005).

8. D. Dieterich, Prog. Org. Coat., 9, 281 (1981).

9. S. Asaoka, T. Sakurai, M. Kitajima, and H. Hanazawa, J. Appl. Polym. Sci., 73, 741 (1999).

10. B. K. Kim and J. C. Lee, J. Polym. Sci., Part A: Polym. Chem., 34, 1095 (1996).

11. S. Turri, M. Levi, and T. Trombetta, J. Appl. Polym. Sci., 93, 136 (2004).

12. Y. S. Kwak, S. W. Park, Y. H. Lee, and H. D. Kim, J. Appl. Polym. Sci., 89, 123 (2003).

13. T. Tawa and S. Ito, Colloid Polym. Sci., 283, 731 (2005).

14. Y. M. Lee, J. C. Lee, and B. K. Kim, Polymer, 35, 1095 (1994).

15. D. J. Hourston, G. Williams, R. Satguru, J. D. Padget, and D. Pears, J. Appl. Polym. Sci., 66, 2035 (1997).

16. D. J. Hourston, G. D. Williams, R. Satguru, J. C. Padget, and D. Pears, J. Appl. Polym. Sci., 74, 556 (1999).

17. S. L. Hsu, H. X. Xiao, H. H. Szmant, and K. C. Frisch, J. Appl. Polym. Sci., 29, 2467 (1984).

18. J. E. Yang, J. S. Kong, S. W. Park, D. J. Lee, and H. D. Kim, J. Appl. Polym. Sci., 86, 2375 (2002).

19. D. C. Lee, R. A. Register, C. Z. Yang, and S. L. Cooper, Macromolecules, 21, 1005 (1988).

20. Y. Chen and Y. L. Chen, J. Appl. Polym. Sci., 46, 435 (1992).

21. S. A. Chen and J. S. Hsu, Polymer, 34, 2769 (1993).

22. Y. S. Kwak, S. W. Park, and H. D. Kim, Colloid Polym. Sci., 281, 957 (2003).

23. H. A. Al-salah, K. C. Frisch, H. X. Xiao, and J. A. Mclean Jr., J. Polym. Sci., Part A: Polym. Chem., 25, 2127 (1987).

24. S. A. Chen and J. S. Hsu, Polymer, 34, 2776 (1993).

25. B. K. Kim and J. C. Lee, Polymer, 37, 469 (1996).

26. H. Xiao, H. X. Xiao, K. C. Frisch, and N. Malwitz, J. Appl. Polym. Sci., 54, 1643 (1994). 
The Role of Hard Segment in PUD

27. Y. Wang, C. L. Zhao, and M. A. Winnik, J. Chem. Phys., 95, 2143 (1991).

28. E. M. Boczar, B. C. Dionne, Z. Fu, A. B. Kirk, P. M. Lesko, and A. D. Koller, Macromolecules, 26, 5772 (1993).

29. Y. Wang and M. A. Winnik, J. Phys. Chem., 97, 2507 (1993). 